\title{
Risk factor analysis of kyphotic malalignment after cervical intramedullary tumor resection in adults
}

\author{
Satoshi Nori, MD, PhD, ${ }^{1}$ Akio Iwanami, MD, PhD, ${ }^{1}$ Akimasa Yasuda, MD, PhD, ${ }^{1}$ \\ Narihito Nagoshi, MD, PhD, ${ }^{1}$ Nobuyuki Fujita, MD, PhD, ${ }^{1}$ Tomohiro Hikata, MD, PhD, ${ }^{1}$ \\ Mitsuru Yagi, MD, PhD, ${ }^{1}$ Takashi Tsuji, MD, PhD, ${ }^{1}$ Kota Watanabe, MD, PhD, ${ }^{1}$ \\ Suketaka Momoshima, MD, PhD, ${ }^{2}$ Morio Matsumoto, MD, PhD, ${ }^{1}$ Masaya Nakamura, MD, PhD, ${ }^{1}$ and \\ Ken Ishii, MD, PhD' ${ }^{1}$
}

Departments of ${ }^{1}$ Orthopedic Surgery and ${ }^{2}$ Radiology, Keio University School of Medicine, Tokyo, Japan

\begin{abstract}
OBJECTIVE A number of studies have reported that surgery for cervical intramedullary tumors via the posterior approach can result in postoperative sagittal malalignment of the cervical spine; however, the risk factors remain unclear. The purpose of this study was to investigate the changes in cervical spinal alignment after surgery for cervical intramedullary tumors in adults and to elucidate the risk factors for cervical spinal sagittal misalignment.

METHODS Data for the period from April 2001 to December 2011 for all adults who had undergone surgery for cervical intramedullary spinal cord tumors at a single institution were retrospectively analyzed to determine the postoperative changes in cervical spine alignment. Patients younger than 20 years of age and those who required postoperative radiotherapy were excluded from the study. Patients were divided into 2 groups according to tumor location: upper tumor (U) group, in which the central region of the tumor was above the C-5 level; and lower tumor (L) group, in which the central region of the tumor was at or below the $\mathrm{C}-5$ level. Changes in alignment of the cervical spine were measured on plain lateral radiographs. Data on atrophy of the deep extensor muscles (DEMs), tumor location, detachment of the DEMs from the C-2 spinous process, the C2-7 angle before surgery, patient age at surgery, tumor histology, patient sex, tumor size, and number of laminae affected were reviewed for each patient, and the correlation of each of these factors with cervical spinal malalignment was evaluated using statistical analysis.
\end{abstract}

RESULTS The 54 adults eligible for analysis had a mean age of 49.1 years. Ependymoma was the most common cervical intramedullary tumor (63.0\%) in this series. In the tumor location $U$ group, the kyphotic angle of the $\mathrm{C} 2-7$ spinal segments increased after surgery $\left(-5.8^{\circ} \pm 2.8^{\circ}\right)$. In contrast, in the $L$ group, the $C 2-7$ lordotic angle increased after surgery $\left(6.4^{\circ} \pm 2.6^{\circ}\right)$. In the univariate analysis, atrophy of the DEMs, detachment of the DEMs from the C-2 spinous process, and an upper cervical location of the tumor were identified as factors significantly correlated with the development of cervical spinal kyphosis after surgery. Multiple linear regression analysis revealed the following as risk factors for kyphotic change of the cervical spine after surgery: 1$)$ atrophy of the DEMs after surgery $(\beta=-0.54, p<0.01)$, and 2$)$ detachment of the DEMs from the $C-2$ spinous process $(\beta=-0.37, p<0.01)$.

CONCLUSIONS Atrophy of the DEMs after surgery and detachment of the DEMs from the $\mathrm{C}-2$ spinous process are directly related to the risk of cervical spinal kyphosis after surgery for cervical intramedullary tumors in adults. Therefore, preservation of the DEMs, especially those attached to the C-2 spinous process, is important for the prevention of kyphotic malalignment of the cervical spine after surgery for intramedullary tumors.

https://thejns.org/doi/abs/10.3171/2017.4.SPINE16956

KEY WORDS cervical intramedullary tumor; cervical alignment; kyphosis; deep extensor muscles; oncology

$\mathrm{I}$ NTRAMEDULLARY spinal cord tumors are relatively rare neoplasms that account for $2 \%-4 \%$ of all central nervous system tumors. ${ }^{8,33}$ They are less common in adults than in children, accounting for $20 \%$ of all adult and $35 \%$ of all pediatric spinal tumors. ${ }^{3,5}$ With advances in the microsurgical techniques for resection of these tumors, the management paradigm for these tumors has shifted to aggressive treatment with radical resection. ${ }^{7,8,23}$ With this approach, long-term survival and quality of life for patients have improved after surgery. ${ }^{7,8,23,33}$ Although current

ABBREVIATIONS CIST = cervical intramedullary spinal cord tumor; DEM = deep extensor muscle; $I C C=$ intraclass correlation coefficient; JOA = Japanese Orthopaedic Association; $L=$ lower tumor; $U=$ upper tumor.

SUBMITTED August 15, 2016. ACCEPTED April 13, 2017.

INCLUDE WHEN CITING Published online September 8, 2017; DOI: 10.3171/2017.4.SPINE16956. 
treatment is aimed at radical or subtotal removal of these tumors, the postoperative development of progressive spinal deformities such as kyphosis is well recognized in children; such deformity has been reported to develop in $22 \%-100 \%$ of patients undergoing surgery for intradural spinal tumors. ${ }^{12,13,20,23,38}$ According to other studies, however, spinal deformity occurs at a rate of about $10 \%$ following surgery for intradural spinal tumors (including intramedullary tumors and extramedullary tumors) in adults. ${ }^{9,26}$ But no studies have examined the frequency of change in spinal alignment after surgery for intramedullary tumors in adults. Some pediatric studies have attempted to identify clinical predictors of spinal deformities after surgery for intramedullary tumors of mixed spinal regions, that is, tumors located in the cervical or thoracic spine level. But such studies may be inappropriate because the biomechanical properties of different spinal regions are different ${ }^{38}$ and because the etiology of any deformities developing after surgery may differ among the various spinal regions. Furthermore, while a number of studies have reported on the development of cervical spinal deformities following surgery for cervical spinal cord tumors in adults, ${ }^{9,16,29}$ the tumors in these studies included intramedullary tumors and intradural extramedullary tumors, as well as extradural tumors. For intradural extramedullary tumors and extradural tumors, especially dumbbell tumors, there is a substantial risk of spinal deformities such as enlargement of the posterior arch and intervertebral foramina, as well as vertebral scalloping. In addition, the facet joint must sometimes be sacrificed for tumor resection. These factors confound any analysis of the pure effect of tumors inside the spinal cord because they can also affect the risk of cervical spine misalignment after surgery.

Since previous studies aimed at identifying risk factors for the development of misalignment of the spine have included tumors located in different spinal regions and patients of various age groups and with various pathologies, their validity and conclusions remain under debate. The purpose of the present study was to identify clinical predictors for the development of sagittal misalignment of the cervical spine following surgery for cervical intramedullary tumors in adults.

\section{Methods}

\section{Subjects}

Data for the period from April 2001 to December 2011 for all adults with cervical intramedullary spinal cord tumors (CISTs) who had undergone surgery at a single academic institution (Keio University Hospital) were retrospectively reviewed for the development of a cervical alignment change following treatment. Patients with cervicothoracic tumors (in which the central region of the tumor was the thoracic level), intradural extramedullary spinal cord tumors, and extradural spinal cord tumors were excluded. Patients younger than 20 years of age and those who required postoperative radiotherapy were also excluded. Patients were evaluated using the Japanese Orthopaedic Association (JOA) scoring system for cervical myelopathy both preoperatively and at 2 weeks postoperatively.

\section{Radiological Assessment}

Prior to surgery, plain lateral radiographs and MR images were obtained in all patients. Postoperatively, plain lateral radiographs and MR images were obtained at annually scheduled follow-up appointments to assess for the presence of cervical malalignment and tumor recurrence. According to the tumor location on the sagittal T2-weighted and gadolinium-enhanced MR images obtained before surgery, patients were divided into 2 groups: upper tumor (U) group, in which the central region of the tumor was above the C-5 level; and lower tumor (L) group, in which the central region of the tumor was at or below the C-5 level. Tumor size was defined as the longitudinal extent (number of vertebral columns) of tumors as assessed on the sagittal gadolinium-enhanced MR images. The sagittal T2-weighted MR images were also used for assessment of tumor size if the gadolinium-enhanced MR images were difficult to evaluate.

To identify changes in the curvature of the cervical spine, lateral cervical radiographs obtained at the final follow-up at least 1 year after surgery were compared with those obtained preoperatively. Curvature of the cervical spine was determined in the upright neutral position by measuring the tangential lines along the posterior borders of the C-2 and C-7 vertebral bodies, the C-2 and C-5 vertebral bodies, or the $\mathrm{C}-5$ and $\mathrm{C}-7$ vertebral bodies $(\mathrm{C} 2-7$ angle, C2-5 angle, and C5-7 angle, respectively). For a few patients who were unable to stand, we used the sitting neutral position. According to a previous study on alignment change after cervical spinal cord tumor resection, a C-2 laminectomy causes the greatest local kyphosis at the C4-5 level, whereas a C-7 laminectomy causes the greatest local lordosis at the C5-6 level, ${ }^{16}$ suggesting that the apex of the cervical sagittal alignment change after upper or lower laminectomies would be located at the C-5 level. Hence, we measured curvature of the cervical spine at $\mathrm{C} 2-5$ and $\mathrm{C} 5-7$ separately.

To quantify damage to the deep extensor muscles (DEMs), the muscle atrophy rate was calculated for each patient from the cross-sectional areas of the DEMs from C-2/C-3 to C-6/C-7 measured on the preoperative and postoperative (at the final follow-up at least 1 year after surgery) axial T2-weighted MR images obtained at 3 different intervertebral levels: the intervertebral level corresponding to the central region of the tumor and 1 level above and 1 below the level corresponding to the central region of the tumor. Analysis was achieved by manually tracing defined regions of interest within the fascial borders of the DEMs (semispinalis cervicis and multifidus muscles) bilaterally on the axial T2-weighted images (See Fig. 5D-I for an example, the area surrounded by the white line). The sum of these 3 cross-sectional areas was regarded as the total area for each patient. Cross-sectional areas of the DEMs were measured as previously described with slight modifications. ${ }^{6,21,25,30}$ The rate of muscle atrophy was calculated using the following formula, as previously described: ${ }^{30}(1-$ total postoperative area/total preoperative area) $\times 100$. A spine surgeon not directly involved in these surgeries (S.N.) measured the area of the DEMs at 3 different time points by using ImageJ software (Scion Corp., http://rsb.info.nih.gov/ij/). The average of the 
3 measurements was used as the area of the DEMs. The intraobserver reliability tested by the intraclass correlation coefficient $(1,1)$ and ICC $(1,3)$ formula was 0.83 and 0.94 , respectively. To assess the interobserver error, 60 randomly chosen axial T2-weighted MR images were measured independently by 3 spine surgeons not directly involved in these surgeries (S.N., A.I., and A.Y.). The interobserver reliability tested by $\operatorname{ICC}(2,1)$ and $\operatorname{ICC}(2,3)$ formula was 0.85 and 0.94 , respectively.

\section{Surgical Technique}

For approaching the CISTs, osteoplastic laminoplasty spanning the length of the tumor was performed. For the osteoplastic laminoplasty, only the medial facet joint was exposed by subperiosteal paraspinal muscle dissection, and an effort was made to preserve the facet joint capsule in every case. No facetectomy was performed in any of the patients during surgery. We performed French-door laminoplasty according to the method described by Kurokawa, ${ }^{19}$ with some modifications. For tumorectomy from the C-2 to C-7 levels, after detaching the bilateral paravertebral muscles from the spinous processes, the laminae were split in the midline by oscillating the wire. Bilateral gutters were created as hinges at the borders of the laminae and facets. After the halves of the laminae were elevated, tumorectomy was performed. For the C-1 level tumorectomy, a C-1 laminectomy was performed. Ultrasonic aspiration was sometimes used to excavate tumor from the inside outward until its interface with the white matter was reached. Sensory evoked and motor evoked potentials were used for monitoring. Resection was deemed complete once the white matter interface was reached. At the end of the procedure, the split halves of the laminae were replaced and secured in place by anchoring sutures (Fig. 1). If the DEMs were detached from the C-2 spinous process during the procedure, reconstruction of extensor muscles was performed with suturing to the $\mathrm{C}-2$ spinous process. No patient in this study had detachment of the semispinalis capitis muscles. Gross-total resection was at- tempted in all cases. The same senior spine surgeons with expertise in spinal cord tumor surgery performed the operations in all cases.

\section{Statistical Analysis}

Statistical analyses were performed using the SPSS software (version 22, SPSS Inc.). A number of pre-, intra-, and postoperative variables were hypothesized to be associated with the risk of a C2-7 cervical alignment change after surgery for CIST. We analyzed these variables: atrophy of the DEMs, tumor location in the cervical spine, detachment of the DEMs from the C-2 spinous process, C2-7 angle before surgery, age at surgery, tumor histology, patient sex, tumor size, and number of laminae affected. Univariate analysis (correlation analysis) was conducted using all the variables except for tumor histology; the Kruskal-Wallis nonparametric test was used for the univariate analysis of tumor histology. Factors with $\mathrm{p}<$ 0.25 identified from the univariate analysis were entered into the multiple linear regression analysis. Differences were considered significant at $\mathrm{p}<0.05$.

\section{Results \\ Patient Population}

None of the patients required tumor resection combined with instrumented fixation. The study population of 54 patients included 38 males and 16 females, with a mean age of $49.1 \pm 6.7$ years (range $21-77$ years) at the time of surgery. The mean duration of follow-up was 80.4 \pm 10.9 months (range 30-144 months). None of the patients had any intrinsic bony lesions potentially affecting spinal alignment. The mean pre- and postoperative JOA scores were $12.5 \pm 3.3$ and $12.3 \pm 3.6$, respectively. Clinical details for all patients are summarized in Table 1. There were 33 patients in the tumor location U group and 21 patients in the L group. The CISTs included hemangioma in 7 patients $(13.0 \%)$, hemangioblastoma in $7(13.0 \%)$, schwannoma in $1(1.8 \%)$, ependymoma in $34(63.0 \%)$,

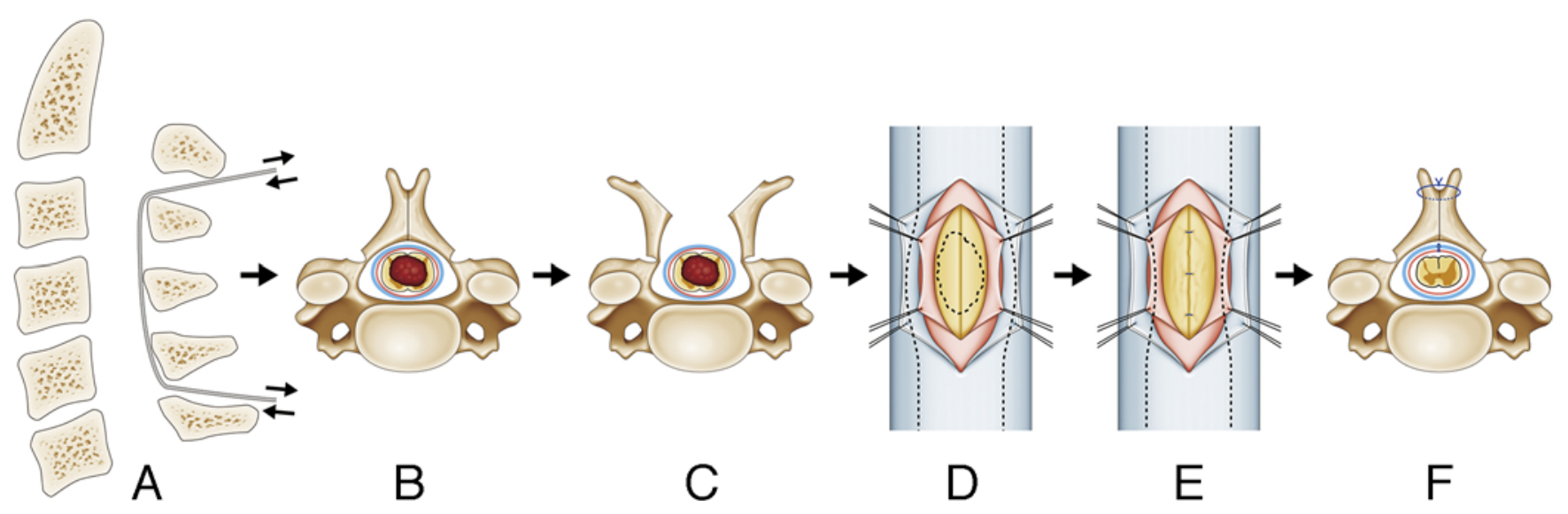

FIG. 1. Surgical technique. French-door laminoplasty spanning the length of the tumor was performed for approaching the tumor. After detachment of the bilateral paravertebral muscles from the spinous processes, the centers of the laminae were cut (A). Bilateral gutters were created as hinges at the borders of the laminae and facets (B). After the halves of the laminae were elevated (C), tumorectomy was performed ( $\mathbf{D}$ and $\mathbf{E})$. The split halves of the laminae were replaced and secured in place by anchoring sutures at the end of the procedure (F). Copyright Satoshi Nori. Published with permission. Figure is available in color online only. 
subependymoma in $1(1.9 \%)$, and astrocytoma in 4 (7.4\%). During the operations, detachment of the DEMs from the C-2 spinous process was performed in 26 patients (48.1\%).

\section{Cervical Alignment Change After Surgery}

In the $\mathrm{U}$ group, kyphotic malalignment of the $\mathrm{C} 2-7$ spinal levels developed $\left(-5.8^{\circ} \pm 2.8^{\circ}\right)$. In contrast, in the $\mathrm{L}$ group, an increase in the $\mathrm{C} 2-7$ lordotic angle was observed after surgery $\left(6.4^{\circ} \pm 2.6^{\circ}\right.$; Figs. 2 and $\left.3 \mathrm{~A}\right)$. We found the same tendency for the C2-5 angle as for the C2-7 angle: We observed kyphosis of the C2-5 segment in the $\mathrm{U}$ group but lordosis of this spinal segment in the $\mathrm{L}$ group after surgery $\left(-5.7^{\circ} \pm 2.2^{\circ}\right.$ and $7.1^{\circ} \pm 1.4^{\circ}$, respectively; Fig. 3B). On the other hand, we observed slight kyphotic malalignment of the C5-7 segment in the L group after surgery but almost no alignment change in the $\mathrm{U}$ group $\left(-2.3^{\circ} \pm 1.7^{\circ}\right.$ and $-0.7^{\circ} \pm 1.3^{\circ}$, respectively; Fig. $\left.3 \mathrm{C}\right)$.

\section{Detachment of DEMs From C-2 Spinous Process and Development of Kyphotic Malalignment After Surgery}

We also analyzed the relationship between detachment of the DEMs from the C-2 spinous process and cervical alignment change after surgery. Detachment of the DEMs from the C-2 spinous process (detached group) increased the rate of development of kyphosis at the C2-7 spinal levels after surgery $\left(-8.4^{\circ} \pm 3.1^{\circ}\right)$, whereas in the patient group in which the DEMs were not detached from the C-2 spinous process (nondetached group), increased lordosis of the C2-7 spinal segment was noted $\left(6.3^{\circ} \pm 2.1^{\circ}\right)$. We found the same tendency for the C2-5 angle as for the C2-7 angle: We observed kyphosis of the C2-5 segment in the detached group but lordosis of this spinal segment in the nondetached group after surgery $\left(-7.9^{\circ} \pm 2.3^{\circ}\right.$ and $4.5^{\circ} \pm 4.7^{\circ}$, respectively). On the other hand, we observed slight kyphotic malalignment of the C5-7 segment in both groups after surgery $\left(-0.4^{\circ} \pm 1.5^{\circ}\right.$ and $-2.1^{\circ} \pm 2.1^{\circ}$, respectively).

\section{Risk Factors of Kyphotic Malalignment After Surgery}

We performed statistical analyses to identify the risk factors for C2-7 malalignment after surgery. Univariate analyses revealed atrophy of the DEMs after surgery as being significantly correlated with kyphotic malalignment after surgery ( $r=-0.67, \mathrm{p}<0.01$; Fig. 4). Furthermore, an upper tumor location as well as detachment of the DEMs from C-2 was significantly correlated with the risk of kyphotic malalignment after surgery $(r=-0.37, p<0.01 ; r$ $=-0.55, \mathrm{p}<0.01$, respectively). None of the other factors were statistically significantly related, as shown by the $p$ values: $\mathrm{C} 2-7$ angle before surgery, $\mathrm{p}=0.11$; number of laminae affected, $\mathrm{p}=0.17$; tumor size, $\mathrm{p}=0.33$; age at surgery, $\mathrm{p}=0.88$; tumor histology, $\mathrm{p}=0.47$; patient sex, $\mathrm{p}=$ 0.29 ; preoperative JOA score, $\mathrm{p}=0.13$; postoperative JOA score, $\mathrm{p}=0.32$ (Table 2$)$.

Next, we analyzed risk factors for the development of kyphosis after surgery by using multiple linear regression analysis. Interestingly, atrophy of the DEMs after surgery $(\beta=-0.56, p<0.01)$ and detachment of the DEMs from the $\mathrm{C}-2$ spinous process $(\beta=-0.37, \mathrm{p}<0.01)$ increased the risk of kyphotic malalignment after surgery. None of the other examined factors were significantly associated with this risk (Table 3).

\section{Illustrative Case}

A 39-year-old man (Case 35) with an ependymoma belonging to the $\mathrm{U}$ group underwent $\mathrm{C} 3-6$ laminoplasty for gross-total resection (Fig. 5A). In this case, we detached the DEMs from the C-2 spinous process to secure the operative field. A preoperative lateral plain radiograph showed a lordotic angle of $0.4^{\circ}$ of the C2-7 segment (Fig. 5B). However, 2 years 8 months after the surgery, kyphotic malalignment developed at $\mathrm{C} 2-7\left(-27.8^{\circ}\right.$; Fig. 5C). Preoperative and postoperative MRI showed atrophy of the DEMs (Fig. 5D-I) after surgery. The muscle atrophy rate in this patient was $36.7 \%$.

\section{Discussion}

This is the first study focusing on clinical predictors for the development of sagittal misalignment of the cervical spine following surgery for CIST in adults. Here, we revealed that atrophy of the DEMs after surgery and detachment of the DEMs from the C-2 spinous process are directly related to the risk of developing cervical spinal kyphosis after CIST resection in adults.

A previous study showed that the development of spinal deformity after surgery for spinal cord tumors depended on the surgical level and the type of operation performed. ${ }^{16}$ Because we speculated that not only the surgical level but also the tumor level in the spine is associated with the risk of postoperative spinal deformity, we divided the patients into 2 groups according to tumor location in the cervical spine. Previously, most studies have been focused on the change in alignment of the entire $\mathrm{C} 2-7$ segment; ${ }^{17}$ thus, they often failed to detect local alignment changes or compensatory cervical alignment changes after surgery. ${ }^{16}$ By measuring the C2-7, C2-5, and C5-7 angles, we were able to evaluate both local and whole cervical alignment.

Kyphotic change at the C2-7 and C2-5 levels developed in the U group after surgery. In the L group, we observed lordotic change at the C2-7 and C2-5 levels after surgery. Moreover, detachment of the DEMs from the C-2 spinous process increased the $\mathrm{C} 2-7$ and $\mathrm{C} 2-5$ kyphotic angle after surgery, whereas $\mathrm{C} 2-7$ and $\mathrm{C} 2-5$ lordotic changes were observed in the group in which the DEMs were not detached. In a previous study of cervical spinal cord tumor patients who had undergone C-2 laminectomy, kyphosis in the upper cervical spine and a compensatory increase in lordosis of the lower cervical spine were observed. In contrast, in the patients who underwent C-7 laminectomy, local kyphosis developed in the lower cervical spine with a compensatory increase in lordosis of the upper cervical spine. ${ }^{16}$ Thus, the pattern of deformity depends on the laminectomy level. ${ }^{13,34}$ While we did not perform laminectomy, but rather double-door laminoplasty, we did obtain results consistent with those mentioned above. Although other studies have shown the preventive effect of laminoplasty against postoperative spinal deformity, ${ }^{16,23}$ our results indicated that laminoplasty can cause kyphotic change at the surgical level and compensatory lordotic change at other levels. No patient required deformity correction surgeries 
S. Nori et al.

TABLE 1. Clinical profile of patients who underwent surgery for CISTs

\begin{tabular}{|c|c|c|c|c|c|c|c|c|c|}
\hline $\begin{array}{l}\text { Case } \\
\text { No. }\end{array}$ & $\begin{array}{c}\text { Age at } \\
\text { Surgery (yrs) }\end{array}$ & Sex & Pathology & $\begin{array}{l}\text { Tumor } \\
\text { Level }\end{array}$ & $\begin{array}{c}\text { Laminoplasty or } \\
\text { Laminectomy Level }^{*}\end{array}$ & $\begin{array}{l}\text { Detachment of } \\
\text { DEM from C-2 }\end{array}$ & $\begin{array}{c}\mathrm{FU} \\
(\mathrm{mos})\end{array}$ & $\begin{array}{c}\text { Preop C2-7 } \\
\text { Angle }\left({ }^{\circ}\right)\end{array}$ & $\begin{array}{c}\text { Postop C2-7 } \\
\text { Angle }\left({ }^{\circ}\right)\end{array}$ \\
\hline 1 & 61 & $\mathrm{~F}$ & Hemangioma & U, C2-4 & $\mathrm{C} 1-4$ & Yes & 86 & -1.4 & 1.8 \\
\hline 2 & 44 & $\mathrm{~F}$ & Hemangioma & U, C2-5 & $\mathrm{C} 1-5$ & Yes & 81 & 6.5 & 10.1 \\
\hline 3 & 44 & $M$ & Hemangioma & L, C-5 & C4-6 & No & 67 & 2.2 & 2.4 \\
\hline 4 & 38 & $M$ & Hemangioma & U, C-3 & C2-4 & Yes & 48 & 16.8 & 14.5 \\
\hline 5 & 47 & $M$ & Hemangioma & U, C3-4 & C2-4 & Yes & 45 & 2.8 & -1.5 \\
\hline 6 & 30 & $M$ & Hemangioma & L, C6-7 & $\mathrm{C} 6-\mathrm{T} 1$ & No & 33 & 7.8 & 19.3 \\
\hline 7 & 71 & $\mathrm{~F}$ & Hemangioma & L, C6-7 & C6-7 & No & 32 & 35.6 & 36.6 \\
\hline 8 & 29 & $M$ & Hemangioblastoma & $\mathrm{L}, \mathrm{C}-5$ & C4-6 & No & 128 & 13 & 9.3 \\
\hline 9 & 33 & $M$ & Hemangioblastoma & U, C3-5 & C3-7 & No & 115 & 2 & 15.6 \\
\hline 10 & 37 & $M$ & Hemangioblastoma & U, C4-5 & C3-5 & No & 92 & 1.7 & 6.3 \\
\hline 11 & 49 & $\mathrm{~F}$ & Hemangioblastoma & U, C4-5 & C4-6 & No & 80 & 2 & 14.4 \\
\hline 12 & 45 & $M$ & Hemangioblastoma & U, C2-4 & C1-4 & Yes & 74 & 3.8 & 2.2 \\
\hline 13 & 32 & $M$ & Hemangioblastoma & U, C1-2 & $\mathrm{C} 1-3$ & Yes & 62 & 10.1 & -5.4 \\
\hline 14 & 28 & $M$ & Hemangioblastoma & U, C2-5 & $\mathrm{C} 2-5$ & Yes & 57 & 43.8 & 14.3 \\
\hline 15 & 61 & M & Neurinoma & $U, C 2-3$ & $\mathrm{C} 1-3$ & Yes & 66 & 34.9 & 32.5 \\
\hline 16 & 34 & $M$ & Ependymoma & U, C3-4 & $\mathrm{C} 3-\mathrm{T} 2$ & No & 144 & -2.5 & 25 \\
\hline 17 & 52 & $\mathrm{M}$ & Ependymoma & U, C2-3 & $\mathrm{C} 1-4$ & Yes & 140 & 22 & 16 \\
\hline 18 & 24 & $\mathrm{~F}$ & Ependymoma & $\mathrm{L}, \mathrm{C}-5$ & C4-7 & No & 127 & -4 & -15 \\
\hline 19 & 68 & M & Ependymoma & U, C2-4 & $\mathrm{C} 1-5$ & Yes & 120 & 26 & 21.1 \\
\hline 20 & 64 & $M$ & Ependymoma & L, C4-7 & $\mathrm{C} 3-\mathrm{T} 1$ & No & 119 & 0 & 20.6 \\
\hline 21 & 65 & $M$ & Ependymoma & L, C5-7 & $\mathrm{C} 4-\mathrm{T} 1$ & No & 110 & 18 & 36.2 \\
\hline 22 & 41 & $\mathrm{~F}$ & Ependymoma & U, C3-4 & $\mathrm{C} 2-\mathrm{T} 1$ & Yes & 109 & 4 & 4.3 \\
\hline 23 & 62 & $\mathrm{M}$ & Ependymoma & U, C3-4 & C1-6 & Yes & 103 & 33 & 35.6 \\
\hline 24 & 38 & $M$ & Ependymoma & $\mathrm{U}, \mathrm{CO}-3$ & $\mathrm{C} 1-3$ & Yes & 102 & 14 & -5.5 \\
\hline 25 & 54 & M & Ependymoma & L, C6-7 & $\mathrm{C} 4-\mathrm{T} 2$ & No & 100 & 1.9 & 19.1 \\
\hline 26 & 35 & $\mathrm{~F}$ & Ependymoma & U, C4-5 & C3-6 & No & 97 & 10.7 & 10.3 \\
\hline 27 & 36 & $\mathrm{~F}$ & Ependymoma & U, C2-6 & $\mathrm{C} 1-\mathrm{T} 1$ & Yes & 95 & -9.5 & -50.5 \\
\hline 28 & 21 & $M$ & Ependymoma & U, C2-3 & $\mathrm{C} 2-\mathrm{T} 1$ & Yes & 91 & 11.4 & 30.3 \\
\hline 29 & 57 & $M$ & Ependymoma & L, C5-6 & C3-6 & No & 88 & 16.8 & 19.6 \\
\hline 30 & 29 & M & Ependymoma & L, C6-T1 & $\mathrm{C} 4-\mathrm{T} 1$ & No & 85 & 12.7 & 23.4 \\
\hline 31 & 59 & $\mathrm{~F}$ & Ependymoma & L, C6-7 & C4-7 & No & 82 & 3.9 & 4.7 \\
\hline 32 & 45 & $M$ & Ependymoma & $L, C 5-6$ & C4-7 & No & 82 & 11.6 & 6.9 \\
\hline 33 & 66 & $\mathrm{~F}$ & Ependymoma & U, C1-2 & C1-4 & Yes & 78 & 19.9 & 12.8 \\
\hline 34 & 65 & $M$ & Ependymoma & U, C1-2 & C1-6 & Yes & 77 & 31.5 & 39.3 \\
\hline 35 & 39 & $M$ & Ependymoma & U, C3-5 & C3-6 & Yes & 77 & 0.4 & -27.8 \\
\hline 36 & 59 & $M$ & Ependymoma & U, C-2 & $\mathrm{C} 2-3$ & Yes & 76 & 18.3 & 1.9 \\
\hline 37 & 65 & M & Ependymoma & U, C3-4 & C3-5 & No & 75 & 8.4 & 18.7 \\
\hline 38 & 59 & $\mathrm{~F}$ & Ependymoma & U, C2-3 & C2-4 & Yes & 73 & 24.5 & 16.2 \\
\hline 39 & 77 & $\mathrm{~F}$ & Ependymoma & U, C3-4 & $C 2-5$ & Yes & 72 & 30.7 & 17.7 \\
\hline 40 & 65 & $M$ & Ependymoma & $L, C 5-6$ & C4-6 & No & 72 & 3.2 & 7.7 \\
\hline 41 & 41 & $M$ & Ependymoma & L, C4-6 & C3-7 & No & 71 & -1 & 17.5 \\
\hline 42 & 32 & $M$ & Ependymoma & L, C5-6 & C5-7 & No & 63 & 5.5 & 0.2 \\
\hline 43 & 63 & $\mathrm{~F}$ & Ependymoma & U, C1-2 & C1-3 & Yes & 63 & 27.8 & 4.7 \\
\hline 44 & 58 & $\mathrm{~F}$ & Ependymoma & U, C-4 & C3-5 & No & 58 & 20.9 & 18.1 \\
\hline 45 & 57 & $M$ & Ependymoma & U, C-2 & C1-4 & Yes & 57 & 20.1 & 3.3 \\
\hline 46 & 66 & $M$ & Ependymoma & L, C5-6 & C4-6 & No & 51 & 26.8 & 13.1 \\
\hline 47 & 36 & $M$ & Ependymoma & L, C5-T1 & C4-T2 & No & 46 & 20 & 27.4 \\
\hline 48 & 51 & $M$ & Ependymoma & U, C2-6 & $\mathrm{C} 1-7$ & Yes & 41 & 17.4 & -29.8 \\
\hline 49 & 39 & $M$ & Ependymoma & U, C1-2 & C1-3 & Yes & 36 & 17.7 & 13.7 \\
\hline
\end{tabular}

CONTINUED ON PAGE 523 » 
» CONTINUED FROM PAGE 522

TABLE 1. Clinical profile of patients who underwent surgery for CISTs

\begin{tabular}{cccccccccc}
\hline $\begin{array}{c}\text { Case } \\
\text { No. }\end{array}$ & $\begin{array}{c}\text { Age at } \\
\text { Surgery (yrs) }\end{array}$ & Sex & Pathology & $\begin{array}{c}\text { Tumor } \\
\text { Level }\end{array}$ & $\begin{array}{c}\text { Laminoplasty or } \\
\text { Laminectomy Level* }\end{array}$ & $\begin{array}{c}\text { Detachment of } \\
\text { DEM from C-2 }\end{array}$ & $\begin{array}{c}\text { FU } \\
(\text { mos })\end{array}$ & $\begin{array}{c}\text { Preop C2-7 } \\
\text { Angle }\left(^{\circ}\right)\end{array}$ & $\begin{array}{c}\text { Postop C2-7 } \\
\text { Angle }\left(^{\circ}\right)\end{array}$ \\
\hline 50 & 60 & F & Subependymoma & L, C5-7 & C5-T1 & No & 30 & 21.4 & 46.3 \\
\hline 51 & 63 & M & Astrocytoma & L, C6-7 & C5-T2 & No & 121 & 11 & 23.7 \\
\hline 52 & 58 & M & Astrocytoma & U, C2-3 & C1-4 & Yes & 88 & 36.1 & 35.7 \\
\hline 53 & 49 & F & Astrocytoma & L, C4-7 & C4-T1 & No & 87 & 14.6 & 8.9 \\
\hline 54 & 49 & M & Astrocytoma & L, C6-7 & C5-7 & No & 70 & 7.2 & 34.6 \\
\hline
\end{tabular}

FU = follow-up.

* Laminectomy was performed only at C-1.

for cervical malalignment after tumor resection during the study period. However, we think that paresis, dysphagia, and unbearable pain due to the developing cervical malalignment following tumorectomy would be indications for those surgeries.

Next, we analyzed the risk factors for a C2-7 alignment change after surgery using univariate and multivariate analyses. These analyses identified 2 main factors as influencing the risk of kyphotic change after tumor resection: 1) atrophy of the DEMs, and 2) detachment of the DEMs from the C-2 spinous process. Notably, atrophy of the DEMs after surgery was found to be significantly as- sociated with the risk of postoperative kyphotic alignment change. From a biomechanical standpoint, the extensor musculature forces on the cervical spine were analyzed in a previous study, and its authors hypothesized that the semispinalis cervicis and semispinalis capitis muscles were primarily responsible for extension of the cervical spine and head. ${ }^{24}$ Disruption of the extensor musculature caused by muscle detachment during surgery could promote sagittal plane deformity. In another study performed using a 3D computerized biomechanical model, investigators showed that the semispinalis cervicis and semispinalis capitis muscles generate $37 \%$ of the total strength
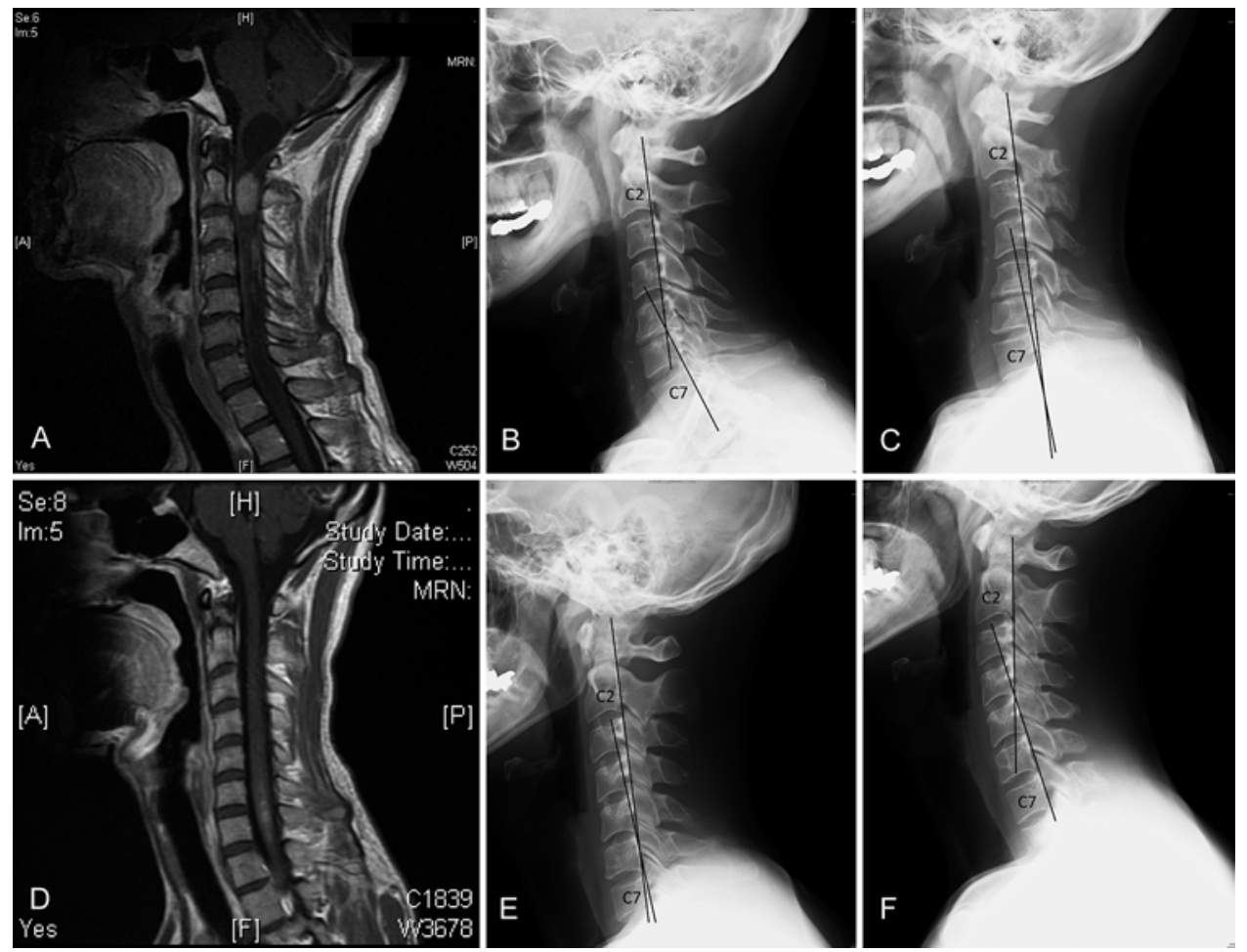

FIG. 2. Representative pre- and postoperative images from the $U$ and $L$ tumor location groups. Case 45. A: Preoperative sagittal gadolinium-enhanced MR image obtained in a 57-year-old man with an ependymoma belonging to the $U$ group who underwent C-1 laminectomy and C2-4 laminoplasty for tumorectomy. B: Preoperative lateral plain radiograph. C: Lateral plain radiograph obtained 2 years 3 months after surgery, showing an increase in the C2-7 kyphotic angle. Case 6. D: Preoperative sagittal gadolinium-enhanced MR image obtained in a 30-year-old man with a hemangioma belonging to the $\mathrm{L}$ group who underwent $\mathrm{C6}$ T1 laminoplasty for tumorectomy. E: Preoperative lateral plain radiograph. F: Lateral plain radiograph obtained 1 year 6 months after surgery, showing an increase in the C2-7 lordotic angle. 

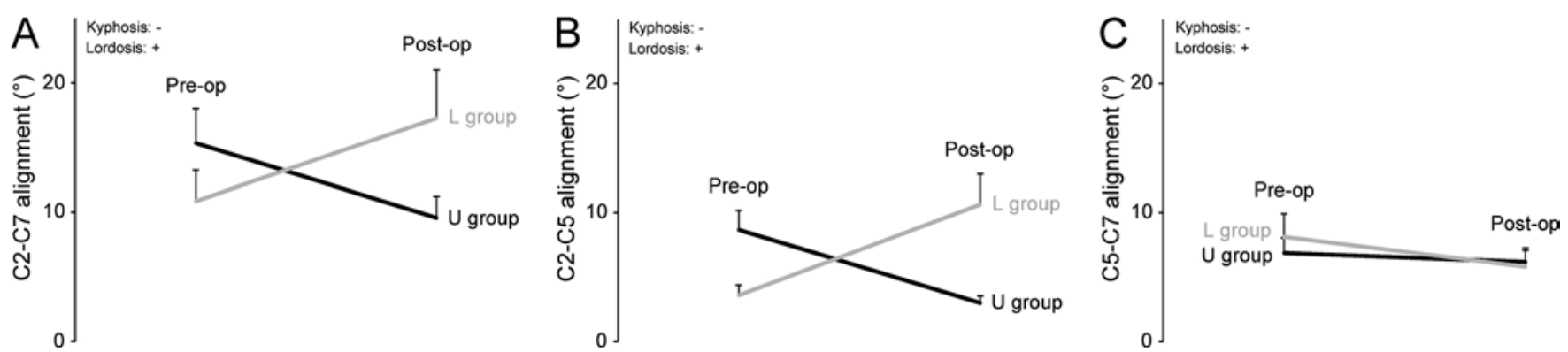

FIG. 3. Cervical alignment change after surgery. A: Preoperative and postoperative $C 2-7$ alignment change in the $U$ and $L$ tumor location groups. In the $U$ group, the $\mathrm{C} 2-7$ kyphotic angle increased postoperatively $\left(-5.8^{\circ} \pm 2.8^{\circ}\right)$. In the $\mathrm{L}$ group, the $\mathrm{C} 2-7$ lordotic angle increased after surgery $\left(6.4^{\circ} \pm 2.6^{\circ}\right)$. B: Postoperative change in the $\mathrm{C} 2-5$ spinal alignment in the $\mathrm{U}$ and $\mathrm{L}$ groups. In the $\mathrm{U}$ group, the $\mathrm{C} 2-7$ kyphotic angle increased postoperatively $\left(-5.2^{\circ} \pm 2.2^{\circ}\right)$. In the $\mathrm{L}$ group, the $\mathrm{C} 2-5$ lordotic angle increased after surgery $\left(7.1^{\circ} \pm 1.4^{\circ}\right)$. C: Preoperative and postoperative C5-7 alignment change in the $U$ and $\mathrm{L}$ groups. While there was almost no change in alignment in the $\mathrm{U}$ group $\left(-0.7^{\circ} \pm 1.3^{\circ}\right)$, slight cervical kyphosis was observed in the $\mathrm{L}$ group $\left(-2.3^{\circ} \pm 1.7^{\circ}\right)$.

produced by all the neck muscles in isometric neck extension. ${ }^{36}$ Moreover, a previous cadaveric study showed that cervical instability is primarily caused by detachment of the semispinalis cervicis muscle from the C-2 spinous process. ${ }^{1}$ The C- 2 vertebral level has the largest spinous process, which serves as the site of attachment for more extensor muscles than any other cervical vertebral spinous process. It plays a principal role as a lever arm. ${ }^{32}$ In one study that analyzed cervical instability after laminectomy for spinal cord tumor resection, the C-2 laminectomy was found to be directly related to the development of cervical instability; this might be explained by the fact that C-2 laminectomy causes a reduction in the area of insertion of the semispinalis cervicis muscle. ${ }^{17}$ Therefore, several authors have advocated laminoplasty with reattachment of the removed muscles to the C-2 spinous process or laminoplasty with a DEM-preserving procedure for all patients who require C-2 decompression. . $^{15,16,22,24,32}$ In the present study, although we reattached the DEMs to the C-2 spinous process, postoperative kyphotic malalignment was still observed. Hence, once the DEMs are detached from the C-2 spinous process, reattachment of the muscles may not be effective in preventing postoperative cervical malalignment. This is consistent with a previous study comparing the cervical alignment change between open-door

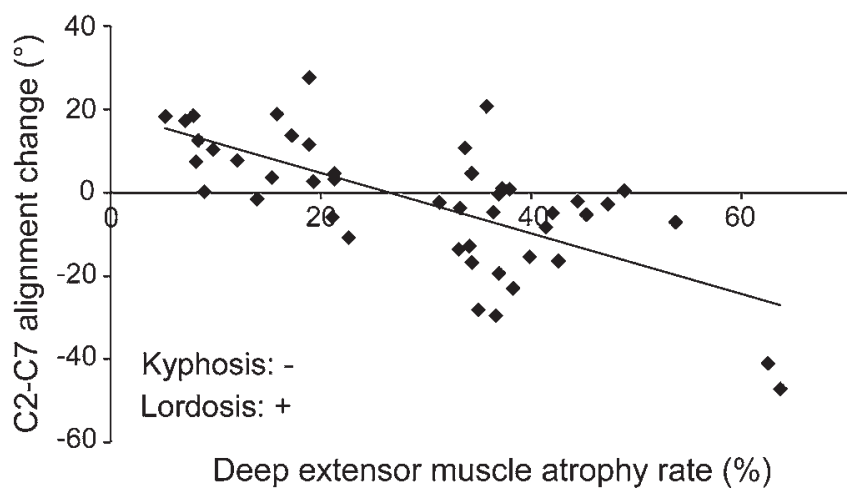

FIG. 4. Correlation between the risk of cervical spinal misalignment and atrophy of the DEMs. Analysis revealed that atrophy of the DEMs at the tumor level was strongly correlated with the development of cervical kyphosis after surgery $(r=-0.67, p<0.01)$. laminoplasty involving elevation of the C-3 lamina with reattachment of the DEMs to the $\mathrm{C}-2$ spinous process and open-door laminoplasty with a C-3 dome laminotomy or laminectomy to completely preserve the insertion of the DEMs to C-2.14

Our statistical analyses identified tumor location, C2-7 angle before surgery, tumor size, tumor histology, age at surgery, patient sex, and number of laminae affected as not significantly associated with the risk of alignment change of the cervical spine following surgery. Previous studies have shown that a preexisting kyphotic deformity tends to increase the risk of malalignment of the cervical spine after surgery. ${ }^{17,38}$ In the present study, however, we found no significant relationship between the C2-7 angle before surgery and the risk of postoperative cervical spinal malalignment. This difference could perhaps be explained by the low incidence of preoperative cervical malalignment in our patients; only 5 of the 54 patients showed kyphotic malalignment of the cervical spine before surgery, and the maximum kyphotic angle measured preoperatively was only $-9.5^{\circ}$. Therefore, we believe that the absence of any remarkable kyphotic deformity before surgery may explain why the preoperative $\mathrm{C} 2-7$ angle was not identified as a risk factor for cervical spinal malalignment after surgery.

Spinal deformities in children can be caused by spinal cord lesions alone, even in the absence of surgical interven-

TABLE 2. Univariate correlation analyses of C2-7 alignment

\begin{tabular}{lcc}
\hline \multicolumn{1}{c}{ Characteristic } & $r$ & $p$ Value \\
\hline Atrophy of DEMs & -0.67 & $8.42 \mathrm{E}-08$ \\
\hline Detachment of DEMs from C-2 & -0.55 & $1.60 \mathrm{E}-05$ \\
\hline Upper localization of tumor & -0.37 & $6.30 \mathrm{E}-03$ \\
\hline C2-7 angle before surgery & -0.22 & 0.11 \\
\hline No. of laminae affected & 0.19 & 0.17 \\
\hline Size of tumors & 0.14 & 0.33 \\
\hline Age at surgery & 0.02 & 0.88 \\
\hline Sex & 0.15 & 0.29 \\
\hline Preop JOA score & -0.22 & 0.13 \\
\hline Postop JOA score & -0.15 & 0.32 \\
\hline
\end{tabular}


TABLE 3. Multiple linear regression analyses of C2-7 kyphotic change

\begin{tabular}{lcc}
\hline \multicolumn{1}{c}{ Characteristic } & $\beta$ & $p$ Value \\
\hline Atrophy of DEMs & -0.56 & $2.00 \mathrm{E}-06$ \\
\hline Detachment of DEMs from C-2 & -0.37 & $7.35 \mathrm{E}-04$ \\
\hline Upper localization of tumor & & 0.43 \\
\hline C2-7 angle before surgery & & 0.53 \\
\hline No. of laminae affected & & 0.42 \\
\hline Preop JOA score & & 0.17 \\
\hline
\end{tabular}

tion. ${ }^{20,35}$ Some previous studies have speculated that compression of the motor neurons in the anterior horn causes cervical muscle denervation and weakness, which can lead to cervical spinal deformities. ${ }^{10,34}$ However, even though gross-total resection was attempted in all patients in the present study, there was no correlation between tumor size and cervical alignment change. This discrepancy may be attributable to anatomical differences between children and adults such as the horizontal cervical spine facets, the lax ligamentous structures, and the growing vertebral column in children. It has been reported that a young age is one of the risk factors for cervical spinal deformities after surgery for spinal tumors. Pediatric patients are known to be at the greatest risk for developing deformities, followed
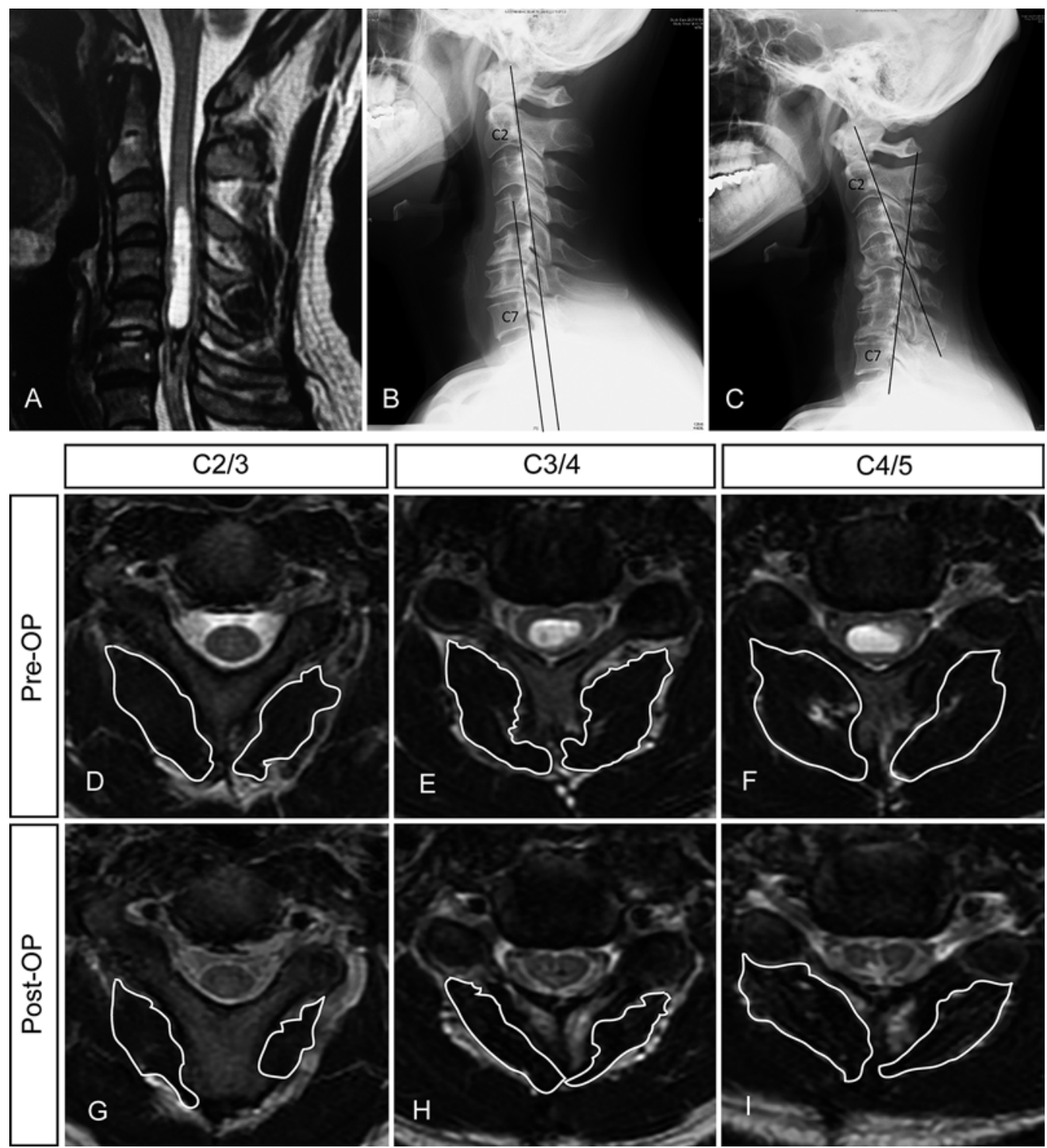

FIG. 5. Case 35. A: Preoperative sagittal T2-weighted MR image obtained in a 39-year-old man with an ependymoma belonging to the $\mathrm{U}$ group who underwent C3-6 laminoplasty for gross-total resection of the tumor. B: Preoperative lateral plain radiograph. C: Lateral plain radiograph obtained 2 years 8 months after surgery, showing an increase in the C2-7 kyphotic angle. D-F: Preoperative axial T2-weighted MR images obtained at the C2-3, C3-4, and C4-5 intervertebral levels. G-I: Postoperative images obtained at the same vertebral levels. White lines show the areas of measurement of the DEMs. Muscle atrophy of the DEMs was observed after surgery. 
by young adults $(<25$ years old), who also have an elevated risk as compared with that in older adults. ${ }^{26,37}$ Since our study was focused on adults with CIST, only 1 young adult patient and no pediatric patients were included in this study. This could explain the absence of any significant correlation between age and the risk of cervical spinal alignment change observed in our study.

While some studies have shown no correlation between the number of laminae affected and the incidence of cervical deformity, ${ }^{4,37}$ another study has reported that the number of laminae affects the risk of cervical spinal malalignment after spinal surgery. ${ }^{17}$ Note, however, that tumors in the latter study included not only intramedullary tumors but also intradural extramedullary tumors and extradural tumors. Hence, there is a substantial risk of spinal deformities due to the bone instability caused by enlarging tumors as well as by sacrificing the facet joint during tumorectomy. These factors confound any analysis of the pure effect of the number of laminae affected and cause the discrepancy in our results that the number of laminae affected did not correlate with cervical alignment change.

Another possible risk factor that has been associated with a cervical alignment change after surgery for CIST in adults is the extent of destruction of the facet joints. Biomechanically, spinal instability increases after laminectomy when at least $50 \%$ of the facet joints are removed. ${ }^{27,39} \mathrm{It}$ has also been reported that cervical instability is most frequent and most severe when the facet joints are destroyed by tumor or surgery. ${ }^{17}$ Since our series only included intramedullary tumors, we did not have to sacrifice the facet joints in any of our cases during surgery, nor were the facet joints destroyed by tumor. Therefore, we excluded destruction of the facet joints as a variable from our risk factor analyses. Radiation therapy has also been documented as a risk factor, both experimentally and clinically, for the development of spinal deformity in children and adults. The reported incidence of spinal deformity after radiation therapy in previous studies is about $60 \% .^{2,11,18,28}$ Since we excluded from our series those patients who had undergone radiation therapy, we also eliminated this factor from our risk factor analysis.

\section{Study Limitations}

This study has several limitations. The major limitation is its inherent nature as a retrospective study. Another limitation is the small sample size. Given the lack of long-term surgical outcome data in most patients, it was difficult to evaluate the effect of postoperative cervical malalignment on long-term postoperative functional and quality-of-life outcomes.

\section{Conclusions}

Following surgery for CIST in adults, kyphotic change at the surgical level and compensatory lordotic change at other levels were often observed. Statistical analyses to identify factors that might be related to the C2-7 alignment change observed after surgery revealed that atrophy of the DEMs after surgery and detachment of the DEMs from the C-2 spinous process are directly related to the risk of developing cervical kyphosis. On the other hand, tumor location, C2-7 angle before surgery, tumor size, tumor histology, age at surgery, patient sex, or number of laminae affected were not significantly associated with cervical malalignment after surgery for CIST in adults.

To avoid cervical spinal malalignment after surgery for CIST, we suggest considering preservation of the DEMs (especially those attached to the C-2 spinous process) during the tumor resection, such as by muscle-preserving posterior arch recapping. ${ }^{31}$ Alternatively, posterior fusion might be considered for the patients whose DEMs are detached from the $\mathrm{C}-2$ spinous process.

\section{References}

1. Arima T: [Changes in the cervical spine after laminectomy.] No Shinkei Gaisyou 1:71-78, 1969 (Jpn)

2. Arkin AM, Simon N: Radiation scoliosis; an experimental study. J Bone Joint Surg Am 32A:396-401, 1950

3. Barker DJ, Weller RO, Garfield JS: Epidemiology of primary tumours of the brain and spinal cord: a regional survey in southern England. J Neurol Neurosurg Psychiatry 39:290296, 1976

4. Bell DF, Walker JL, O'Connor G, Tibshirani R: Spinal deformity after multiple-level cervical laminectomy in children. Spine (Phila Pa 1976) 19:406-411, 1994

5. Bowers DC, Weprin BE: Intramedullary spinal cord tumors. Curr Treat Options Neurol 5:207-212, 2003

6. Choi MK, Kim SB, Park CK, Lee SH, Jo DJ: The relation of deep paraspinal muscles' cross-sectional area of the cervical spine and bone union in anterior cervical decompression and fusion: a retrospective study. World Neurosurg 96:91-100, 2016

7. Constantini S, Houten J, Miller DC, Freed D, Ozek MM, Rorke LB, et al: Intramedullary spinal cord tumors in children under the age of 3 years. J Neurosurg 85:1036-1043, 1996

8. Constantini S, Miller DC, Allen JC, Rorke LB, Freed D, Epstein FJ: Radical excision of intramedullary spinal cord tumors: surgical morbidity and long-term follow-up evaluation in 164 children and young adults. J Neurosurg 93 (2 Suppl):183-193, 2000

9. Cristante L, Herrmann HD: Surgical management of intramedullary spinal cord tumors: functional outcome and sources of morbidity. Neurosurgery 35:69-76, 1994

10. Epstein JA: The surgical management of cervical spinal stenosis, spondylosis, and myeloradiculopathy by means of the posterior approach. Spine (Phila Pa 1976) 13:864-869, 1988

11. Evans AE, Norkool P, Evans I, Breslow N, D’Angio GJ: Late effects of treatment for Wilms' tumor. A report from the National Wilms' Tumor Study Group. Cancer 67:331-336, 1991

12. Fassett DR, Clark R, Brockmeyer DL, Schmidt MH: Cervical spine deformity associated with resection of spinal cord tumors. Neurosurg Focus 20(2):E2, 2006

13. Fraser RD, Paterson DC, Simpson DA: Orthopaedic aspects of spinal tumors in children. J Bone Joint Surg Br 59:143151,1977

14. Iizuka H, Nakajima T, Iizuka Y, Sorimachi Y, Ara T, Nishinome M, et al: Cervical malalignment after laminoplasty: relationship to deep extensor musculature of the cervical spine and neurological outcome. J Neurosurg Spine 7:610-614, 2007

15. Iizuka H, Shimizu T, Tateno K, Toda N, Edakuni H, Shimada $\mathrm{H}$, et al: Extensor musculature of the cervical spine after laminoplasty: morphologic evaluation by coronal view of the magnetic resonance image. Spine (Phila Pa 1976) 26:22202226, 2001

16. Inoue A, Ikata T, Katoh S: Spinal deformity following surgery for spinal cord tumors and tumorous lesions: analysis 
based on an assessment of the spinal functional curve. Spinal Cord 34:536-542, 1996

17. Katsumi Y, Honma T, Nakamura T: Analysis of cervical instability resulting from laminectomies for removal of spinal cord tumor. Spine (Phila Pa 1976) 14:1171-1176, 1989

18. Katzman H, Waugh T, Berdon W: Skeletal changes following irradiation of childhood tumors. J Bone Joint Surg Am 51:825-842, 1969

19. Kurokawa T: [Double door laminoplasty by longitudinal splitting of the spinous process.] Bessatsu Seikeigeka 2:234-240, 1982 (Jpn)

20. Lunardi P, Licastro G, Missori P, Ferrante L, Fortuna A: Management of intramedullary tumours in children. Acta Neurochir (Wien) 120:59-65, 1993

21. Matsumoto M, Ichihara D, Okada E, Chiba K, Toyama Y, Fujiwara H, et al: Cross-sectional area of the posterior extensor muscles of the cervical spine in whiplash injury patients versus healthy volunteers - 10 year follow-up MR study. Injury 43:912-916, 2012

22. Matsuzaki H, Hoshino M, Kiuchi T, Toriyama S: Dome-like expansive laminoplasty for the second cervical vertebra. Spine (Phila Pa 1976) 14:1198-1203, 1989

23. McGirt MJ, Chaichana KL, Atiba A, Bydon A, Witham TF, Yao KC, et al: Incidence of spinal deformity after resection of intramedullary spinal cord tumors in children who underwent laminectomy compared with laminoplasty. J Neurosurg Pediatr 1:57-62, 2008

24. Nolan JP Jr, Sherk HH: Biomechanical evaluation of the extensor musculature of the cervical spine. Spine (Phila Pa 1976) 13:9-11, 1988

25. Okada E, Matsumoto M, Ichihara D, Chiba K, Toyama Y, Fujiwara H, et al: Cross-sectional area of posterior extensor muscles of the cervical spine in asymptomatic subjects: a 10-year longitudinal magnetic resonance imaging study. Eur Spine J 20:1567-1573, 2011

26. Papagelopoulos PJ, Peterson HA, Ebersold MJ, Emmanuel PR, Choudhury SN, Quast LM: Spinal column deformity and instability after lumbar or thoracolumbar laminectomy for intraspinal tumors in children and young adults. Spine (Phila Pa 1976) 22:442-451, 1997

27. Raynor RB, Pugh J, Shapiro I: Cervical facetectomy and its effect on spine strength. J Neurosurg 63:278-282, 1985

28. Riseborough EJ: Irradiation induced kyphosis. Clin Orthop Relat Res (128):101-106, 1977

29. Sciubba DM, Chaichana KL, Woodworth GF, McGirt MJ, Gokaslan ZL, Jallo GI: Factors associated with cervical instability requiring fusion after cervical laminectomy for intradural tumor resection. J Neurosurg Spine 8:413-419, 2008

30. Shiraishi T, Fukuda K, Yato Y, Nakamura M, Ikegami T: Results of skip laminectomy-minimum 2-year follow-up study compared with open-door laminoplasty. Spine (Phila Pa 1976) 28:2667-2672, 2003

31. Shiraishi T, Kato M, Yato Y, Ueda S, Aoyama R, Yamane J, et al: New techniques for exposure of posterior cervical spine through intermuscular planes and their surgical application. Spine (Phila Pa 1976) 37:E286-E296, 2012

32. Shiraishi T, Yato Y: New double-door laminoplasty proce- dure for the axis to preserve all muscular attachments to the spinous process: technical note. Neurosurg Focus 12(1):E9, 2002

33. Shrivastava RK, Epstein FJ, Perin NI, Post KD, Jallo GI: Intramedullary spinal cord tumors in patients older than 50 years of age: management and outcome analysis. J Neurosurg Spine 2:249-255, 2005

34. Sim FH, Svien HJ, Bickel WH, Janes JM: Swan-neck deformity following extensive cervical laminectomy. A review of twenty-one cases. J Bone Joint Surg Am 56:564-580, 1974

35. Tachdjian MO, Matson DD: Orthopaedic aspects of intraspinal tumors in infants and children. J Bone Joint Surg Am 47:223-248, 1965

36. Vasavada AN, Li S, Delp SL: Influence of muscle morphometry and moment arms on the moment-generating capacity of human neck muscles. Spine (Phila Pa 1976) 23:412-422, 1998

37. Yasuoka S, Peterson HA, MacCarty CS: Incidence of spinal column deformity after multilevel laminectomy in children and adults. J Neurosurg 57:441-445, 1982

38. Yeh JS, Sgouros S, Walsh AR, Hockley AD: Spinal sagittal malalignment following surgery for primary intramedullary tumours in children. Pediatr Neurosurg 35:318-324, 2001

39. Zdeblick TA, Zou D, Warden KE, McCabe R, Kunz D, Vanderby R: Cervical stability after foraminotomy. A biomechanical in vitro analysis. J Bone Joint Surg Am 74:22-27, 1992

\section{Disclosures}

The authors report no conflict of interest concerning the materials or methods used in this study or the findings specified in this paper.

\section{Author Contributions}

Conception and design: Iwanami, Nori, Nakamura. Acquisition of data: Iwanami, Nori, Yasuda, Momoshima. Analysis and interpretation of data: Nori. Drafting the article: Iwanami, Nori, Nagoshi, Nakamura. Critically revising the article: Iwanami, Nori, Nagoshi. Reviewed submitted version of manuscript: Iwanami, Nori, Yasuda, Nagoshi, Fujita, Hikata, Yagi, Tsuji, Watanabe, Matsumoto, Nakamura, Ishii. Statistical analysis: Nori. Study supervision: Iwanami, Yasuda, Nagoshi, Fujita, Hikata, Yagi, Tsuji, Watanabe, Matsumoto, Nakamura, Ishii.

\section{Supplemental Information \\ Previous Presentations}

Portions of this work were presented at the 29th Annual Meeting of the Cervical Spine Research Society-European Section held in Bordeaux, France, on May 30, 2013.

\section{Correspondence}

Akio Iwanami, Department of Orthopedic Surgery, Keio University School of Medicine, 35 Shinanomachi, Shinjuku, Tokyo 1608582, Japan. email: iwanami@1998.jukuin.keio.ac.jp. 